\title{
Identification of Anti-Diabetic Phytocompounds from Ficus racemosa and its Validation through In Silico Molecular Modeling
}

\author{
Thirumalaisamy Rathinavel ${ }^{1,2^{*}}$, Subramanian Ammashi ${ }^{2}$, \\ Selvankumar Thangaswamy ${ }^{1}$ and Gnanendra Shanmugam ${ }^{3}$ \\ ${ }^{1}$ Department of Biotechnology, Mahendra Arts \& Science College (Autonomous), \\ Namakkal (Dt) -637 501,Tamil Nadu, India. \\ ${ }^{2}$ Department of Biochemistry, Rajah Serfoji Government College (Autonomous), \\ Thanjavur (Dt) - 613 005, Tamil Nadu, India \\ ${ }_{3}^{3}$ Microbial Genomics Laboratory, Department of Biotechnology, Yeungnam University, \\ Gyeongsan, South Korea.
}

\begin{abstract}
In the present study, anti-diabetic phyto compounds of Ficus racemosa bark methanolic extract was screened through GCMS and evaluated its anti-diabetic potential in vitro and in silico (molecular docking and DFT analysis) approaches. The anti-diabetic phyto compounds $\beta$-Sitosterol, $\beta$-amyrin, betulinic acid and stigmasterol were explored through GCMS analysis. In vitro anti-diabetic $\alpha$-amylase inhibitory effect of the plant (IC50 $19.50 \mu \mathrm{g}$ ) was found equipotent when compared with standard acarbose drug (IC50 $11.25 \mu \mathrm{g}$ ). In silico molecular docking study of Ficus racemosa phytocompounds and reference standard drug acarbose with four crucial targets of diabetes (GLP-1, GSK, GK \& IRTK) revealed that phytocompound $\beta$-amyrin shows highest binding affinity with all four screened targets $-6.9,-9.1,-8.9,-10.7 \mathrm{kcal} / \mathrm{mol}$ than standard drug acarbose $-4.7,-8.1,-7.7 \&-8.8 \mathrm{kcal} / \mathrm{mol}$ respectively. Further DFT analysis of top 3 ant-diabetic phytocompounds ( $\beta$-amyrin, betulinic acid and stigmasterol) of F.raemosa and standard acarbose was done. It was found that $\beta$-amyrin possess more stability and biological activity as it shows less energy gap, low hardness, and more softness $-0.06277 \mathrm{eV}, 0.031385 \mathrm{eV}$ and $31.86235 \mathrm{eV}$ than reference standard acarbose possess more energy gap, more hardness, and low softness -0.24436 $\mathrm{eV}, 0.12218 \mathrm{eV}$ and $8.18464 \mathrm{eV}$ respectively.
\end{abstract}

KEYWORDS: Ficus racemosa, $\beta$-amyrin, Acarbose, DFT, HOMO-LUMO

https://doi.org/10.29294/IJASE.5.4.2019.1085-1098

(C) 2019 Mahendrapublications.com, All rights reserved

\section{INTRODUCTION}

Medicinal plants continue to play a central role in the healthcare system of large proportions of the world's population. A significant number of modern pharmaceutical drugs are thus based on or derived from medicinal plants. The need to document plant uses and attempt to confirm their efficacy remains urgent. The primary benefits of using plant derived medicines are that they are relatively safer than synthetic alternatives, offering profound therapeutic benefits and more affordable treatment. The isolation and identification of the active principles and elucidation of the mechanism of action of a drug is of paramount importance.

Diabetes mellitus is a debilitating and often lifethreatening disorder with increasing incidence throughout the world. It is considered as one of the five leading causes of death in the world [1, 2]. In modern medicine no satisfactory effective therapy is still available to cure diabetes mellitus [3]. There is increasing demand by patients to use natural products with antidiabetic activity due to side effects associated with the use of insulin and oral hypoglycemic agents $[4,5,6]$. Better alternatives from plant origin are clearly needed for better management of diabetes because of high cost and poor availability of current therapies for many rural populations, particularly in developing countries. Plant materials which are being used as traditional medicine for the treatment of diabetes are considered one of the good sources for a new drug or a lead to make a new drug. A proper scientific evaluation for screening of plant by pharmacological tests followed by chemical investigations is necessary and scientific investigation of traditional herbal remedies for diabetes may provide valuable leads for the development of alternative drugs and strategies.

Ficus racemosa plant is frequently found around the water stream and is also cultivated in villages for shade and its edible fruits $[7,8]$. The tree is medium tall $(18 \mathrm{~m})$ with quite green foliage that provides good shade. The leaves are dark green, 7.5-10 cm long, ovate or elliptic. The fruit receptacles are $2-5 \mathrm{~cm}$ in diameter, pyriform, in large clusters, arising from main trunk or large branches. The fruits resemble the figs and are green when raw, turning orange, dull reddish or dark crimson on ripening [9]. The seeds are tiny, innumerable, and grain-like. The roots are long and brownish in color. Bark is reddish grey or greyish green, soft surface, uneven and often cracked,

*Corresponding Author: tmalaisamy@gmail.com

Received: 10.02.2019 Accepted: 20.05.2019 Published on: 27.05.2019 
$0.5-1.8 \mathrm{~cm}$ thick [10].

The stem bark of Ficus racemosa Linn contains tannin, wax, saponin gluanol acetate, $\beta$-sitosterol , leucocyanidin- $3-0-\beta-D$ - glucopyrancoside, leucopelargonidin $-3-0-\beta-D$ - glucopyranoside, leucopelargonidin $-3-0-\alpha-\mathrm{L}$ - rhamnopyranoside, lupeol, ceryl behenate, lupeol acetate, $\alpha$-amyrin acetate, leucoanthocyanidin and leucoanthocyanin from trunk bark lupeol, $\beta$-sitosterol and stigmasterol were isolated [11]. Bark is highly efficacious in threatened abortion and also recommended in urological disorders, diabetes,hiccough, leprosy, dysentery and piles [12-14]. The decoction of $F$. racemosa bark has shown antidiuretic effect [15]. Ethanol extract of stem bark showed wound healing in excised and incised wound model in rats [16].

In the present study phyto compounds of $F$. racemosa bark extract was identified through GCMS analysis and its anti-diabetic potential of identified phytocompounds validated through in vitro $\alpha$-amylase inhibitory assay and in silico molecular docking, DFT analysis. Thus the present study aims to identify antidiabetic phyto compounds from $F$. racemosa to design novel drug candidate for diabetes.

and aluminium hydroxide molecules condense to form rigid chains of oxygen bonded tetrahedrally with the application of small temperature or even at ambient [4].

In this study, GGBS is used as source material in the geopolymer concrete. The compressive strength of GPC was evaluated using non-destructive testing and destructive testing method. Based on relative literature, the effect of Molarity of $\mathrm{NaOH}$ and curing conditions of GPC on Compressive strength, SRH has been discussed in the following sections.

\section{MATERIALS AND METHODS}

\subsection{Collection of plant and preparation of plant} extract

Ficus racemosa plant bark sample was collected from Salem District, Tamil Nadu, India. The bark sample was washed with running tap water and followed by distilled water to remove impurities and dry the bark sample under shade for 24-48h.The shade dried bark sample were grinded as fine powder for further analysis.

About $50 \mathrm{~g}$ of bark powder was packed with Whatman No 1 filter paper and placed in soxhlet apparatus along with $300 \mathrm{ml}$ of analytical grade methanol. Then the sample was boiled for ten soxhlet cycles to obtain methanolic bark extract of Ficus racemosa and then evaporated under reduced pressure and dried using a rotary evaporator at $55^{\circ} \mathrm{C}$. Then the dried extracts were labeled and stored in sterile screw-capped bottles at $5^{\circ} \mathrm{C}$ in the refrigerator for further use.

\subsection{Identification of Phytocompounds from Ficus} racemosa by GCMS Analysis

Identification of bioactive phytocompounds of Ficus racemosa bark extract was done using Gas Chromatography-Mass Spectrometry (GC-MS) analysis. The interpretation of mass spectrum in GC-
MS was interpreted using the database of National Institute Standard and Technology (NIST). The spectrum of the unknown component from the plant leaf sample was compared with the spectrum of the known components using computer searches on a NIST-2008 version MS data library. Phytocompounds name, molecular weight, molecular formula and their molecular structure from plant leaf sample were ascertained through NIST library computer search.

The bark extracts of Ficus racemosa were prepared for GC-MS analysis by following procedure. $0.1 \mathrm{~g}$ of powdered sample was dissolved in $2 \mathrm{ml}$ of ethanol. One micro liter of sample was injected into the gas chromatography instrument. Separation and analysis of compounds were achieved through the Clarus 680 GC with a fused silica column, packed with Elite-5MS (5\% biphenyl 95\% dimethylpolysiloxane, $30 \mathrm{~m} \times 0.25$ $\mathrm{mm}$ ID $\times 250 \mu \mathrm{m} \mathrm{df}$ ) and the components of plant leaf sample were separated using Helium as carrier gas at a constant flow of $1 \mathrm{ml} /$ minute. The injector temperature was set at $260^{\circ} \mathrm{C}$ during the chromatographic run. The $1 \mu \mathrm{L}$ of leaf extract sample injected into the instrument the oven temperature was as follows: $60^{\circ} \mathrm{C}$ ( 2 minutes); followed by $300^{\circ} \mathrm{C}$ at $10^{\circ} \mathrm{C} \mathrm{min}-1$; and $300^{\circ} \mathrm{C}$, where it was held for 6 minutes. The mass detector conditions were: transfer line temperature $240^{\circ} \mathrm{C}$; ion source temperature $240{ }^{\circ} \mathrm{C}$; and ionization mode electron impact at $70 \mathrm{eV}$, a scan time 0.2 seconds and scan interval of 0.1 seconds and the fragments from 40 to 600 Da.

\subsection{In Vitro Anti-Diabetic Activity By $\alpha$-amylase inhibitory assay}

A starch solution $(1 \% \mathrm{w} / \mathrm{v})$ was prepared by stirring $1 \mathrm{~g}$ starch in $100 \mathrm{ml}$ of $20 \mathrm{mM}$ of phosphate buffer (pH 6.9) containing 6.7mM of sodium chloride. The enzyme solution was prepared by mixing $27.5 \mathrm{mg}$ of porcine pancreatic amylase $\alpha$-amylase (PPA) in $100 \mathrm{ml}$ of $20 \mathrm{mM}$ of phosphate buffer (PBS, pH 6.9) containing $6.7 \mathrm{mM}$ of sodium chloride. To $100 \mu \mathrm{l}$ of $(6.25,12.5,25,50,100 \mu \mathrm{g} / \mathrm{ml})$ plant extracts, $200 \mu \mathrm{l}$ porcine pancreatic amylase was added and the mixture was incubated at $37{ }^{\circ} \mathrm{c}$ for $20 \mathrm{~min}$. To the reaction mixture $100 \mu \mathrm{l}(1 \%)$ starch solution was added and incubated at $37^{\circ} \mathrm{C}$ for $10 \mathrm{~min}$. The reaction was stopped by adding $200 \mu \mathrm{l}$ DNSA (1g of 3,5 di nitro salicylic acid, $30 \mathrm{~g}$ of sodium potassium tartarate and $20 \mathrm{ml}$ of $2 \mathrm{~N}$ sodium hydroxide was added and made up to a final volume of $100 \mathrm{ml}$ with distilled water) and kept it in a boiling water bath for 5 minutes. The reaction mixture diluted with $2.2 \mathrm{ml}$ of water and absorbance was read at $540 \mathrm{~nm}$. For each concentration, blank tubes were prepared by replacing the enzyme solution with $200 \mu \mathrm{L}$ in distilled water. Control, representing 100\% enzyme activity was prepared in a similar manner, without extract. The experiments were repeated thrice using the same protocol [17]. The concentration of the extract required to inhibit $50 \%$ of $\alpha$-amylase activity under the assay conditions was defined as the IC50 value. 


\subsection{MOLECULAR DOCKING}

\subsubsection{Receptors}

To determine the anti-diabetic potential of identified phytocompounds from Ficus racemosa bark extract, the three dimensional structures of four diabetic molecular targets such as Glucagon Like Peptide-1 (GLP-1) (PDBID: 1D0R) and Glycogen synthase kinase-3 beta (GSK) (PDBID: 1H8F), Glucokinase (GK) (PDBID: 1V4S), Insulin Receptor Tyrosine Kinase (IRTK) (PDBID: 2B4S), that plays the crucial role in diabetes mellitus were chosen for docking study and their 3D structures were retrieved from PDB database [18].

\subsubsection{Ligands generation}

Nine identified phytocompounds of Ficus racemosa bark extract through GCMS analysis served as a ligands and their 2D structures were drawn in ACDChemsketch (ACD/ChemSketch Freeware, version 11, 2006) and its SMILES notation was obtained. The SMILES notation was submitted to "Online SMILES convertor and Structure file generator [19] and converted into 3D SDF format.

\subsubsection{Protein-Ligand Interaction Using Autodock}

To explore the binding affinities between receptors (GLP-1, GSK, GK and IRTK) and 09 ligands, an automated flexible docking of ligands was carried out by using AutoDock Vina [20]. The grid map that represents the protein binding sites for docking was calculated with the aid of AutoGrid. The grid size of $52 \times 74 \times 82$ points in each dimension was set for Glucagon Like Peptide-1; the grid size for Glycogen synthase kinase- 3 beta was set to $47 \times 37 \times 42$ points in each dimension; for Glucokinase the grid size was $114 \times 120 \times 69$ and the gird size of $78 \times 87 \times 43$ was set to Insulin receptor Tyrosine Kinase. In all cases the spacing of $0.375 \AA$ A between the grid points was set by using AutoGrid. Gasteiger charges on the atoms of both ligand were calculated by using AutoDock tools. All possible torsions of ligand molecules for the docking algorithm was used through the autotors utility in the AutoDock Tool and docking was carried out with the following parameters: ten docking trials, 150 population size, 250000 maximum number of energy evaluation, 27,000 maximum number of generations, 0.02 mutation rate, 0.8 cross-over rate, 1 elitism value and other parameters as default values. Finally, the docking pose with the better binding affinity score $(\mathrm{kcal} / \mathrm{mol})$ is ranked as the top orientation of the each ligand against each receptor and selected for the binding interaction studies. The docking interactions studies were carried out by using receptor-ligand interaction options in Discovery Studio v2.5.

\subsection{DFT ANALYSIS}

The major Phytocompounds and their relative peak area percentage of Ficus racemosa methanolic bark extract were found to be 4-Isopropenyl cyclohexanone $(7.60 \%)$, Cyclopentane, (2-methyl-1propenyl)- (2.00\%), 4H-Pyran-4-one, 2-methyl-6-
The determination of molecular electrostatic potential (MEP) that indicates the electrophilic and nucleophilic reactive sites of the compounds and the energy gap between highest occupied molecular orbital (HOMO) and lowest unoccupied molecular orbital (LUMO) providing high and low electron density regions on the compounds are performed through Density functional theory (DFT) calculations. The DFT calculations were performed for top 3 scored ant-diabetic phytocompounds ( $\beta$-amyrin, betulinic acid and stigmasterol) of F.raemosa and standard acarbose was done using functional B3LYP with 63IG** basic set in Gaussian 09. The important parameter, HOMO-LUMO orbital energies that are used to assess the ionization energy, electron affinity, electronegativity, electronic chemical potential, molecular hardness, softness and electrophilicity index are calculated to reveal the compounds stability and chemical reactivity.

\section{RESULT \& DISCUSSION}

3.1. Identification of Phytocompounds from Ficus racemosa by GCMS Analysis

The GC-MS analysis of methanolic bark extract of Ficus racemosa revealed the presence of eight phytocompounds by comparing their retention times and interpretation of their mass spectra. The major and minor compounds with their retention times (RT), molecular formula (MF), molecular weights (MW), molecular structure and peak area percentage are presented in Table $1 \& 2$ and their GCMS chromatogram was shown in Figure 1.

\section{MATERIALS}

The materials used for making GGBS based geopolymer concrete specimens were GGBS as the source material, aggregates, alkaline solution, water, and superplasticizer.

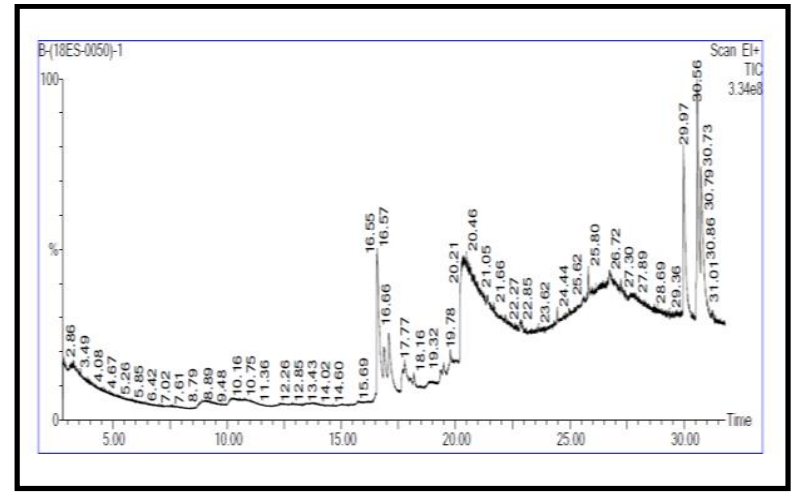

Figure 1- GCMS Chromatogram of Ficus racemosa methanolic bark extract

phenyl- (52.24\%), Benzo [1,2-B:4,3-B'] difuran (2.97\%), Beta-Sitosterol (1.77\%), Stigmasterol (7.35\%), Beta-Amyrin (7.01\%), Betulinic acid (10.40\%), c(14a)-Homo-27-Norgammacer-13-en-21ol, 3-methoxy-3.alpha,21.bet (8.63\%). 
Similar work involving exploring phyto constituents of medicinal plant was done through GCMS analysis and it may useful for finding out active principles of medicinal plant which is responsible for biological properties of the plant [21]. The explored phyto compounds of plant extract may be helpful to identify possible types of interactions with multiple targets of various diseases to design novel lead molecules [22].

Table 1- Phytocompounds identified in the plant Ficus racemosa methanolic bark extract by GC-MS.

\begin{tabular}{|r|c|c|c|c|c|}
\hline S.No & RT & Compound name & MW & MF & $\begin{array}{c}\text { Peak Area } \\
\text { \% }\end{array}$ \\
\hline 1 & 16.569 & 4-Isopropenyl cyclohexanone & 138 & $\mathrm{C}_{9} \mathrm{H}_{14} \mathrm{O}$ & 7.600 \\
\hline 2 & 17.069 & Cyclopentane, (2-methyl-1-propenyl)- & 152 & $\mathrm{C}_{9} \mathrm{H}_{16}$ & 2.001 \\
\hline 3 & 20.460 & 4H-Pyran-4-one, 2-methyl-6-phenyl- & 186 & $\mathrm{C}_{12} \mathrm{H}_{10} \mathrm{O}_{2}$ & 52.248 \\
\hline 4 & 22.166 & Benzo [1,2-B:4,3-B'] difuran & 158 & $\mathrm{C}_{10} \mathrm{H}_{6} \mathrm{O}_{2}$ & 2.971 \\
\hline 5 & 25.802 & $\beta-S i t o s t e r o l$ & 414 & $\mathrm{C}_{29} \mathrm{H}_{50} \mathrm{O}$ & 1.773 \\
\hline 6 & 26.748 & Stigmasterol & 412 & $\mathrm{C}_{29} \mathrm{H}_{48} \mathrm{O}$ & 7.355 \\
\hline 7 & 29.969 & $\beta-$-Amyrin & 426 & $\mathrm{C}_{30} \mathrm{H}_{50} \mathrm{O}$ & 7.013 \\
\hline 8 & 30.564 & Betulinic acid & 456 & $\mathrm{C}_{30} \mathrm{H}_{48} \mathrm{O}_{3}$ & 10.406 \\
\hline 9 & 30.734 & $\mathrm{c}(14 \mathrm{a})-$-Homo-27-Norgammacer-13-en-21-ol, 3- \\
methoxy-3.alpha, 21.bet & 456 & $\mathrm{C}_{31} \mathrm{H}_{52} \mathrm{O}_{2}$ & 8.634 \\
\hline
\end{tabular}

Table 2- The explored Phytocompounds of Ficus racemosa methanolic bark extract through GC-MS analysis

\begin{tabular}{|c|c|c|}
\hline S.No & Compound name & Molecular Structure \\
\hline 1. & 4-Isopropenyl cyclohexanone & \\
\hline 2. & Cyclopentane, (2-methyl-1-propenyl)- & \\
\hline 3. & 4H-Pyran-4-one, 2-methyl-6-phenyl- & \\
\hline 4. & Benzo [1,2-B:4,3-B'] difuran & \\
\hline
\end{tabular}




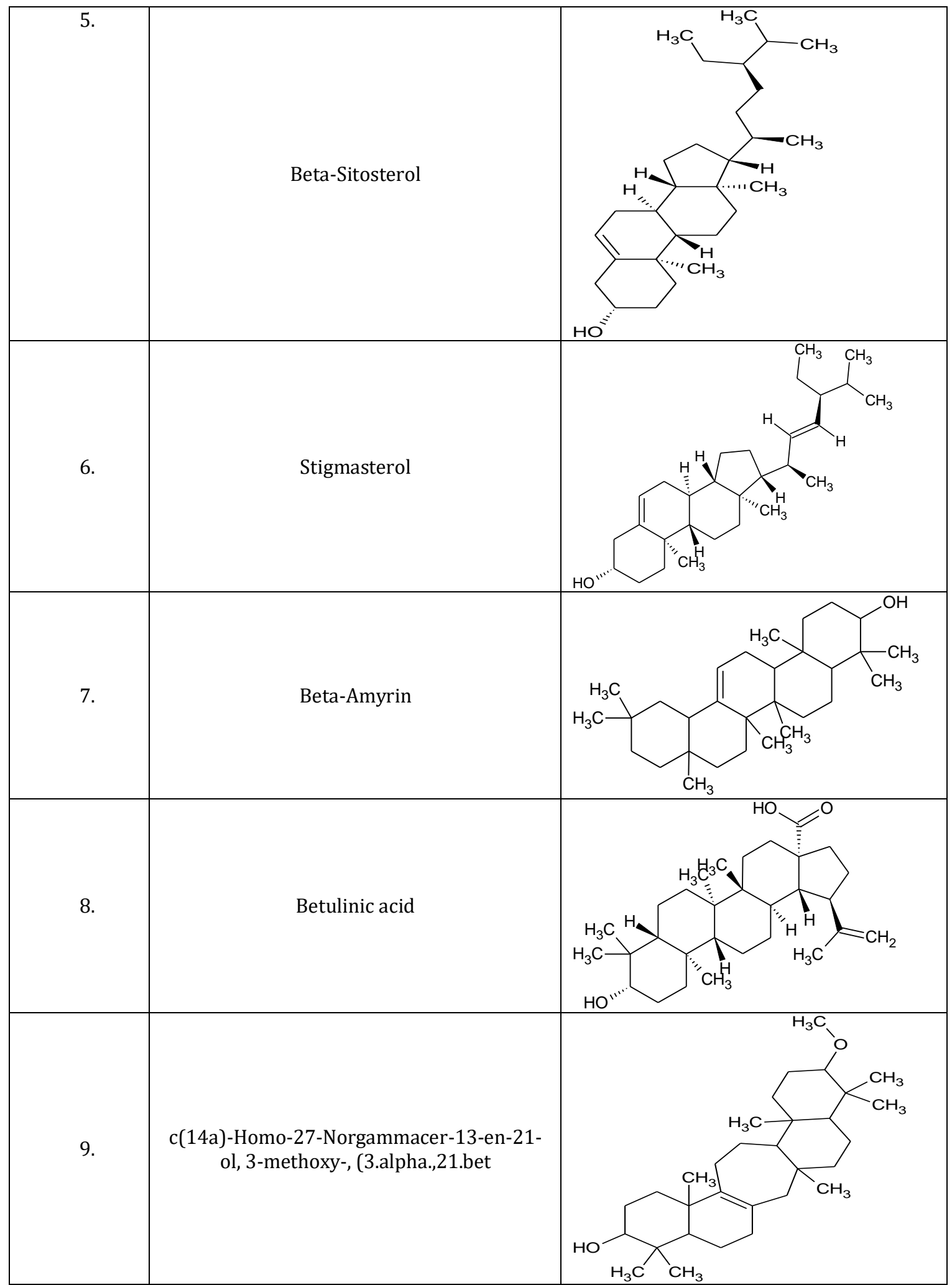

\subsection{In Vitro Anti-Diabetic Activity By $\alpha$-amylase} inhibitory assay

In this study the in vitro $\alpha$-amylase inhibitory activities of the methanolic bark extracts of Ficus racemosa was investigated. The result of experiment showed that, there was a dose-dependent increase in percentage inhibitory activity against $\alpha$-amylase enzyme. The methanolic bark extract (6.25-
$100 \mu \mathrm{g} / \mathrm{ml}$ ) of the plant Ficus racemosa exhibited potent - amylase inhibitory activity in a dose dependent manner. The bark extracts of Ficus racemosa showed inhibitory activity from $32.28 \pm 0.04$ to $72.42 \pm 0.01 \%$ with an IC50 value of $19.50 \mu$ g dry extract (Table 3). Acarbose is a standard drug for $\alpha$ amylase inhibitor. Acarbose showed $\alpha$-amylase inhibitory activity from $40.99 \pm 0.03$ to $83.17 \pm 0.04 \%$ 
with an IC50 value $11.25 \mu \mathrm{g}$. A comparison of $\alpha-$ amylase inhibitory activity between the standard drug and plant extracts has been depicted in Table 3 \& Figure 2.

Table 3- In vitro Anti-diabetic activity of methanolic bark extracts of Ficus racemosa By $\alpha$-amylase inhibitory assay

\begin{tabular}{|c|c|c|c|}
\hline \multirow{2}{*}{ S.No } & $\begin{array}{c}\text { Concentration } \\
\text { of Bark } \\
\text { Extract/ } \\
\text { Standard } \\
(\mu \mathrm{g} / \mathrm{ml})\end{array}$ & \multicolumn{2}{|c|}{ Percentage of $\alpha$-Amylase Inhibition } \\
\cline { 3 - 4 } & 6.25 & $32.28 \pm 0.04$ & Acarbose \\
\hline 1. & 12.5 & $43.38 \pm 0.02$ & $50.99 \pm 0.03$ \\
\hline 2. & 25 & $56.82 \pm 0.02$ & $68.72 \pm 0.01$ \\
\hline 3. & 50 & $65.19 \pm 0.01$ & $76.26 \pm 0.03$ \\
\hline 4. & 100 & $72.42 \pm 0.01$ & $83.17 \pm 0.04$ \\
\hline 5. & $19.50 \mu \mathrm{g}$ & $11.25 \mu \mathrm{g}$ \\
\hline
\end{tabular}

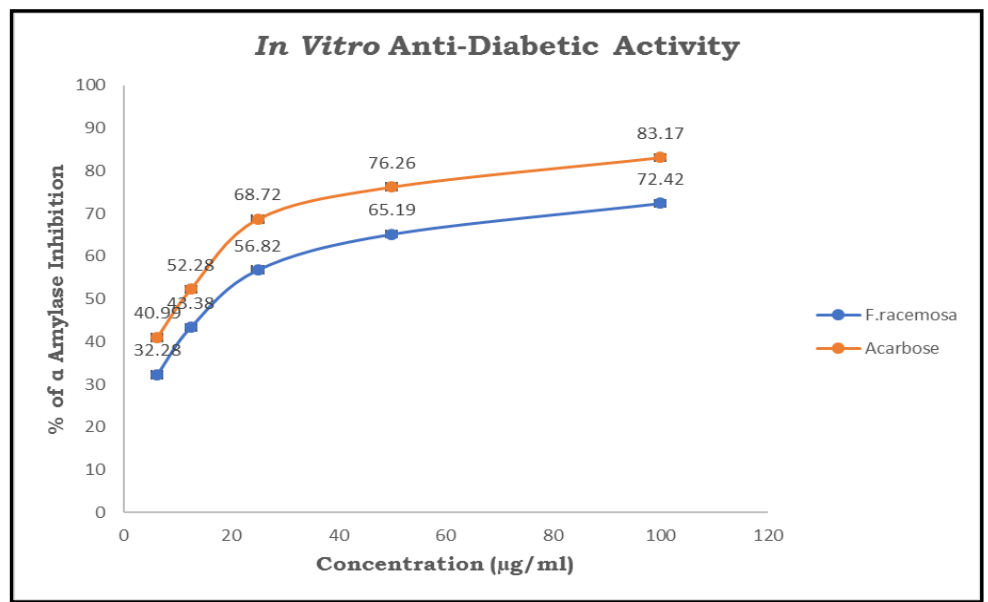

Figure 2 - In vitro Anti-diabetic activity of methanolic bark extracts of Ficus racemosa by $\alpha$-amylase inhibitory assay

\subsection{Molecular Docking Study}

Four diabetic molecular targets such as Glucagon like Peptide-1 (PDBID: 1D0R) and Glycogen synthase kinase-3 beta (PDBID: 1H8F), Glucokinase (PDBID: 1V4S), Insulin receptor Tyrosine Kinase (PDBID: $2 \mathrm{~B} 4 \mathrm{~S})$, that plays the crucial role in diabetes mellitus were chosen for docking study

The 3D structure of Glucagon Like Peptide-1 (GLP1) (PDBID: 1D0R) and Glycogen synthase kinase-3 beta (GSK) (PDBID: 1H8F), Glucokinase (GK) (PDBID: 1V4S), Insulin Receptor Tyrosine Kinase (IRTK) (PDBID: 2B4S) were considered as potential targets and their structural features represents that Glucagon Like Peptide- 1 protein belongs to alpha class as it possess helices only whereas remaining other three diabetic targets belongs to alpha + beta class as it posses helices and sheets (Figure 3 ).

The molecular docking analysis was performed using Autodock Vina program with nine ligands of Ficus racemosa derived phytocompounds against Glucagon Like Peptide-1 (GLP-1), Glycogen synthase kinase-3 beta (GSK), Glucokinase (GK) and Insulin
Receptor Tyrosine Kinase (IRTK) and their binding affinity results were expressed as $\mathrm{K} . \mathrm{cal} / \mathrm{mol}$ were shown in Table 3.

The docking interactions of ligands with Glucagon like Peptide-1 (GLP-1) exhibited the binding affinity ranging from $-3.9 \mathrm{kcal} / \mathrm{mol}$ to $-6.9 \mathrm{kcal} / \mathrm{mol}$. It is observed that the highest binding affinity of -6.9 $\mathrm{kcal} / \mathrm{mol}$ was exhibited by $\beta$-Amyrin than the standard drug acarbose $-4.7 \mathrm{kcal} / \mathrm{mol}$ (Figure 4 ). The interaction of $\beta$-Amyrin is favored by the formation of the alkyl interactions with Phe6, val10, Tyr 13 and Leu14 residues of GLP-1. GLP-1 amino acid Glu15, Gln17 \& Glu21 residues form hydrogen bonds with reference standard drug acarbose with a bond length ranging from 2.00 to 5.35 .

The docking interactions of ligands with Glycogen synthase kinase-3 beta (GSK) exhibited the binding affinity ranging from $-5.1 \mathrm{kcal} / \mathrm{mol}$ to $-9.1 \mathrm{kcal} / \mathrm{mol}$. It is observed that the highest binding affinity of -9.1 $\mathrm{kcal} / \mathrm{mol}$ was exhibited by $\beta$-Amyrin than the standard drug acarbose $-8.1 \mathrm{kcal} / \mathrm{mol}$ (Figure 5). The interaction of $\beta$-Amyrin is favored by the formation of 
the alkyl interactions with Ile62, val70, Lys85, Tyr 134 and Leu188 and hydrogen bond interaction with Pro136 residues of GSK. GSK amino acid Lys85, Val135, Pro136, Lys183 \& Ser261 residues form hydrogen bonds with reference standard drug acarbose with a bond length ranging from 2.11 to 5.38 .

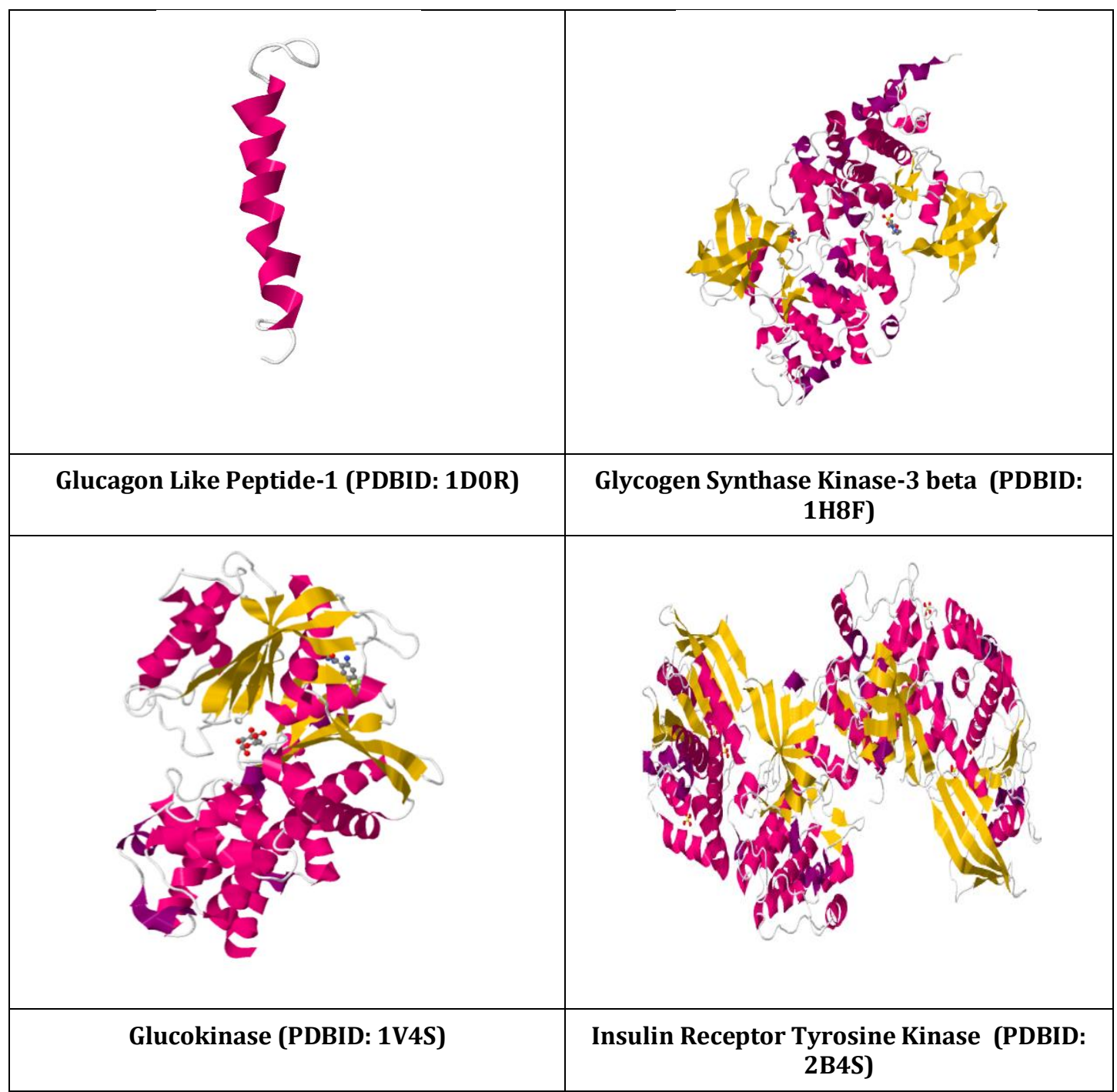

Figure 3. The 3D structure of four potential diabetic drug targets such as Glucagon Like Peptide-1, Glycogen Synthase Kinase-3 $\beta$, Glucokinase, Insulin Receptor Tyrosine Kinase

Table 4 - Binding Affinity for Phytocompounds identified from Ficus racemosa with four diabetic target proteins

\begin{tabular}{|c|c|c|c|c|c|}
\hline \multirow[b]{2}{*}{ S.No } & \multirow[b]{2}{*}{ Phytocompounds / Standard Drug } & \multicolumn{4}{|c|}{ Binding Affinity K.Cal /mol } \\
\hline & & $\begin{array}{c}\text { GLP-1 } \\
\text { (1D0R) }\end{array}$ & $\begin{array}{c}\text { GSK } \\
\text { (1H8F) }\end{array}$ & $\begin{array}{c}\text { GK } \\
(1 \mathrm{~V} 4 S)\end{array}$ & $\begin{array}{l}\text { IRTK } \\
\text { (2B4S) }\end{array}$ \\
\hline 1. & 4-Isopropenyl cyclohexanone & -4.1 & -5.3 & -5.0 & -5.3 \\
\hline 2. & Cyclopentane, (2-methyl-1-propenyl)- & -3.9 & -5.1 & -4.6 & -4.9 \\
\hline 3. & 4H-Pyran-4-one, 2-methyl-6-phenyl- & -4.9 & -7.2 & -6.5 & -7.1 \\
\hline 4. & Benzo [1,2-B:4,3-B'] difuran & -4.2 & -5.7 & -5.9 & -5.8 \\
\hline 5. & $\beta$-Sitosterol & -5.8 & -8.1 & -6.6 & -8.7 \\
\hline 6. & Stigmasterol & -6.1 & -8.9 & -7.1 & -10.0 \\
\hline 7. & $\beta$-Amyrin & -6.9 & -9.1 & -8.2 & -10.7 \\
\hline 8. & Betulinic acid & -6.3 & -8.9 & -7.6 & -9.7 \\
\hline 9. & $\begin{array}{c}\text { c(14a)-Homo-27-Norgammacer-13-en- } \\
\text { 21-ol, 3-methoxy-, (3.alpha.,21.bet }\end{array}$ & ND & ND & ND & ND \\
\hline 10. & Acarbose & -4.7 & -8.1 & -7.7 & -8.8 \\
\hline
\end{tabular}

\section{Thirumalaisamy Rathinavel et al.,}


The docking interactions of ligands with Glucokinase (GK) exhibited the binding affinity ranging from -4.6 $\mathrm{kcal} / \mathrm{mol}$ to $-8.2 \mathrm{kcal} / \mathrm{mol}$. It is observed that the highest binding affinity of $-8.2 \mathrm{kcal} / \mathrm{mol}$ was exhibited by $\beta$-Amyrin than the standard drug acarbose -7.7 $\mathrm{kcal} / \mathrm{mol}$ (Figure 6). The interaction of $\beta$-Amyrin is favored by the formation of the alkyl interactions with Ile225, Lys414 and Leu415 and unfavorable donordonor interaction with Ser151 residues of GK. GK amino acid Arg85, Lys169, Thr228, Gly229, Lys414, Glu440 \& Gly 443 residues form hydrogen bonds with reference standard drug acarbose with a bond length ranging from 2.04 to 5.34 .

The docking interactions of ligands with Insulin Receptor Tyrosine Kinase (IRTK) exhibited the binding affinity ranging from $-4.9 \mathrm{kcal} / \mathrm{mol}$ to -10.7 $\mathrm{kcal} / \mathrm{mol}$. It is observed that the highest binding affinity of $-10.7 \mathrm{kcal} / \mathrm{mol}$ was exhibited by $\beta$-Amyrin than the standard drug acarbose $-8.8 \mathrm{kcal} / \mathrm{mol}$ (Figure 7 ). The interaction of $\beta$-Amyrin is favored by the formation of the alkyl interactions with Arg residues of IRTK from unknown position. IRTK amino acid Arg, Asp, Thr and Glu from unknown positions form hydrogen bonds with reference standard drug acarbose with a bond length ranging from 2.04 to 5.34 .

It was observed that phytocompound $\beta$-Amyrin exhibit highest binding affinity $(-6.9,-9.1,-8.2,-10.7$ $\mathrm{kcal} / \mathrm{mol}$ ) against four diabetic molecular targets such as GLP-1, GSK, GK and IRTK respectively than the reference standard drug acarbose. The phyto compound Betulinic acid exhibit second highest binding affinity $(-6.3 \mathrm{kcal} / \mathrm{mol},-8.9 \mathrm{kcal} / \mathrm{mol} \&-7.6$ $\mathrm{kcal} / \mathrm{mol}$ ) with GLP-1, GSK and GK respectively. Similarly, Stigmasterol exhibit second highest binding affinity $(-10.0 \mathrm{kcal} / \mathrm{mol})$ with IRTK.

Glucokinase (GK, PDB ID: 1V4S) is a monomeric cytoplasmic enzyme found in the liver and pancreas. Its main function is regulation of glucose levels in these organs. Through phosphorylation glucokinase is able to increase the metabolism of glucose. In the liver it increases the synthesis of glycogen and it is the first step in glycolysis, the main producer of ATP in the body $[23,24]$. Therefore, GK would be an ideal drug target for type 2 diabetes (T2D) diseases because of its high impact in glucose homeostasis, and its activation results in lower blood glucose level irrespective of the cause of hyperglycemia.

Glycogen synthase kinases $3 \beta$ (GSK $3 \beta$, PDB: 1Q4L) belongs to the super family of mitogen-activated protein kinase. GSK $3 \beta$ has been implicated in the development of insulin resistance and regulation of glycogen synthesis [25]. It is one of the important targets in the treatment of T2D. Inhibitors of GSK-3 $\beta$ have antidiabetic properties because they improve insulin sensitivity, glycogen synthesis, and glucose metabolism in skeletal muscles of diabetic patients $[26,27]$.
Similar work involving screening antidiabetic activity of Peperomia pellucida constituents was studied using in silico approach [28]. Docking analysis results clearly indicated that Yohimbine has binding energy of $-10.08 \mathrm{cal} / \mathrm{mol}$ possessing high anti-diabetic activity when compared to the standard, Quercetin ($9.62 \mathrm{Kcal} / \mathrm{mol}$ ). Commercially available flavonoids such as biochanin, butein, esculatin, fisetin and herbacetin on the inhibitory effect of AR. The standard used was Eparestat, a known aldose reductase inhibitor. The results revealed that all the selected flavonoids showed binding energy ranging between $9.33 \mathrm{kcal} / \mathrm{mol}$ to $-7.23 \mathrm{kcal} / \mathrm{mol}$ when compared to that of the standard $(-8.73 \mathrm{kcal} / \mathrm{mol})$. Inhibition constant (144.13 $\mu \mathrm{M}$ to $4.98 \mu \mathrm{M})$ and intermolecular energy $(-11.42 \mathrm{kcal} / \mathrm{mol}$ to $-7.83 \mathrm{kcal} / \mathrm{mol})$ of the flavonoids also coincide with the binding energy. Butein, biochanin and herbacetin showed excellent binding interactions with aldose reductase enzyme than the standard when compared to other flavanoids. This is due to the difference in the position of the functional groups in the compounds [29]. The inhibitory effects of phytochemicals present in dietary spices such as Zingiber officinale (ginger), Curcuma longa (turmeric) Allium sativum (garlic) and Trigonellafoenumgraecum (fenugreek) on AR. Molecular docking was performed on phytochemicals such as Gingerenones A, B and C, lariciresinol, quercetin and calebin $\mathrm{A}$ to study protein-ligand interactions [30].

\subsection{Density Functional Theory Analysis}

Density functional theory (DFT), a quantum mechanical approach is used to describe the accurate structural and electronic properties of compounds (in general small molecules). In this study, the electronic distribution information of three best docked phytocompounds of F.racemosa $\beta$-Amyrin, Betulinic acid, Stigmasterol and reference standard acarbose were theoretically determined through orbital energy calculations. The idea on electronic distribution of these compounds could provide the clear picture of protein-ligand interactions and be useful to explore the inhibition potentials of the compounds. The high and low electron density regions of the compounds are computed through highest occupied molecular orbital (HOMO) and lowest unoccupied molecular orbital (LUMO) energies and are shown in Figure 8. The calculated HOMO-LUMO orbital energies are used to estimate the ionization energy, electron affinity, electro negativity, electronic chemical potential, molecular hardness, molecular softness, and Electrophilicity index

The localization of HOMO and LUMO orbitals in the compound is very important. Furthermore, the HOMO and LUMO of a molecule play important roles in revealing its intermolecular interactions, through the interaction between the HOMO of the drug with the LUMO of the receptor and vice versa. Among the compounds, $\beta$-Amyrin $(-0.06277 \mathrm{eV}, 0.031385 \mathrm{eV}$ and 
$31.86235 \mathrm{eV}$ ) showed more stability and biological activity as it shows less energy gap, low hardness, and more softness followed by Betulinic acid $(-0.23987 \mathrm{eV}$, $0.119935 \mathrm{eV}$ and $8.33784 \mathrm{eV}$ ) reference standard acarbose $(-0.24436 \mathrm{eV}, 0.12218 \mathrm{eV}$ and $8.18464 \mathrm{eV})$ and Stigmasterol $(-0.26925 \mathrm{eV}, 0.134625 \mathrm{eV}$ and $7.42804 \mathrm{eV}$ ) (Table 5). Thus the DFT calculations performed here further substantiate our findings in molecular docking.

Similar comparative DFT study of phytochemical constituents of present in the leaves of Curatella americana Linn $\beta$-amyrin and betulinic acid shows lowest value of HOMO $-6.4722 \mathrm{eV}$ and $-6.3092 \mathrm{eV}$ respectively. The antioxidant activity of Curatella Americana L, was performed by the study of quantum chemicals to obtain a relation between electronic properties and antioxidant capacity of the chemical constituents. It was possible to characterize the compounds as well as their characteristics of electro donor/electro accepter compared to the standard compound by DFT analysis [31].
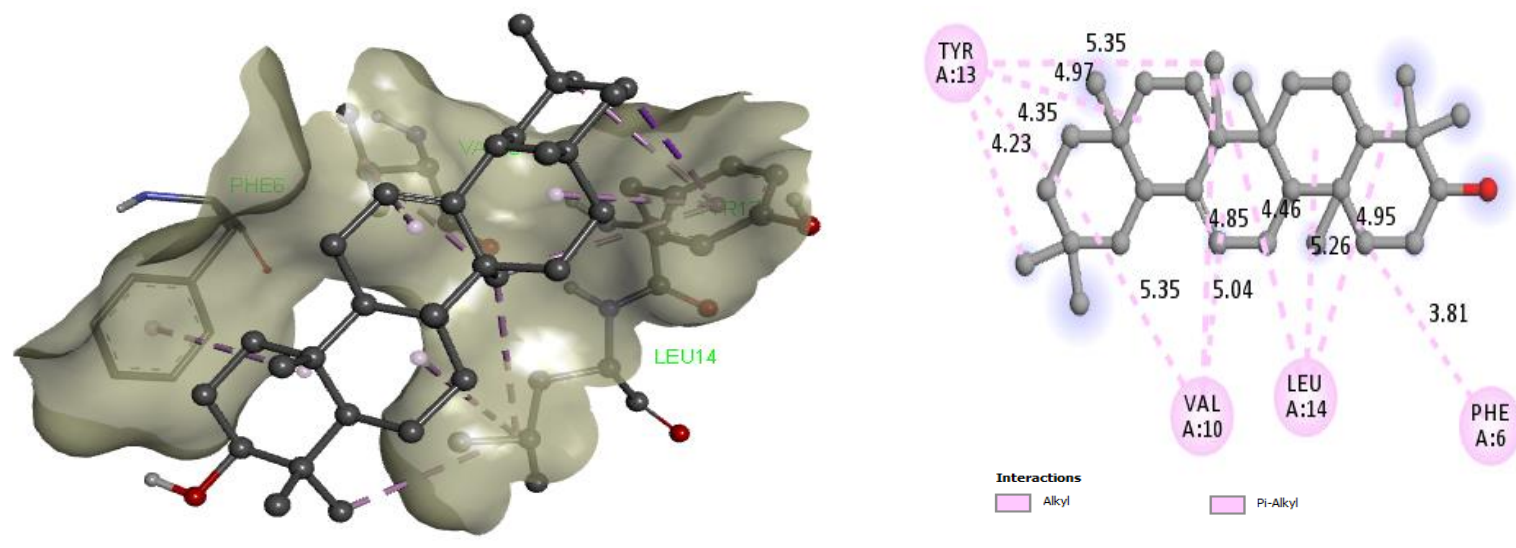

Docking complex and interaction plot for $\beta$-Amyrin with GLP-1

(Binding affinity: $-6.1 \mathrm{kcal} / \mathrm{mol}$ )
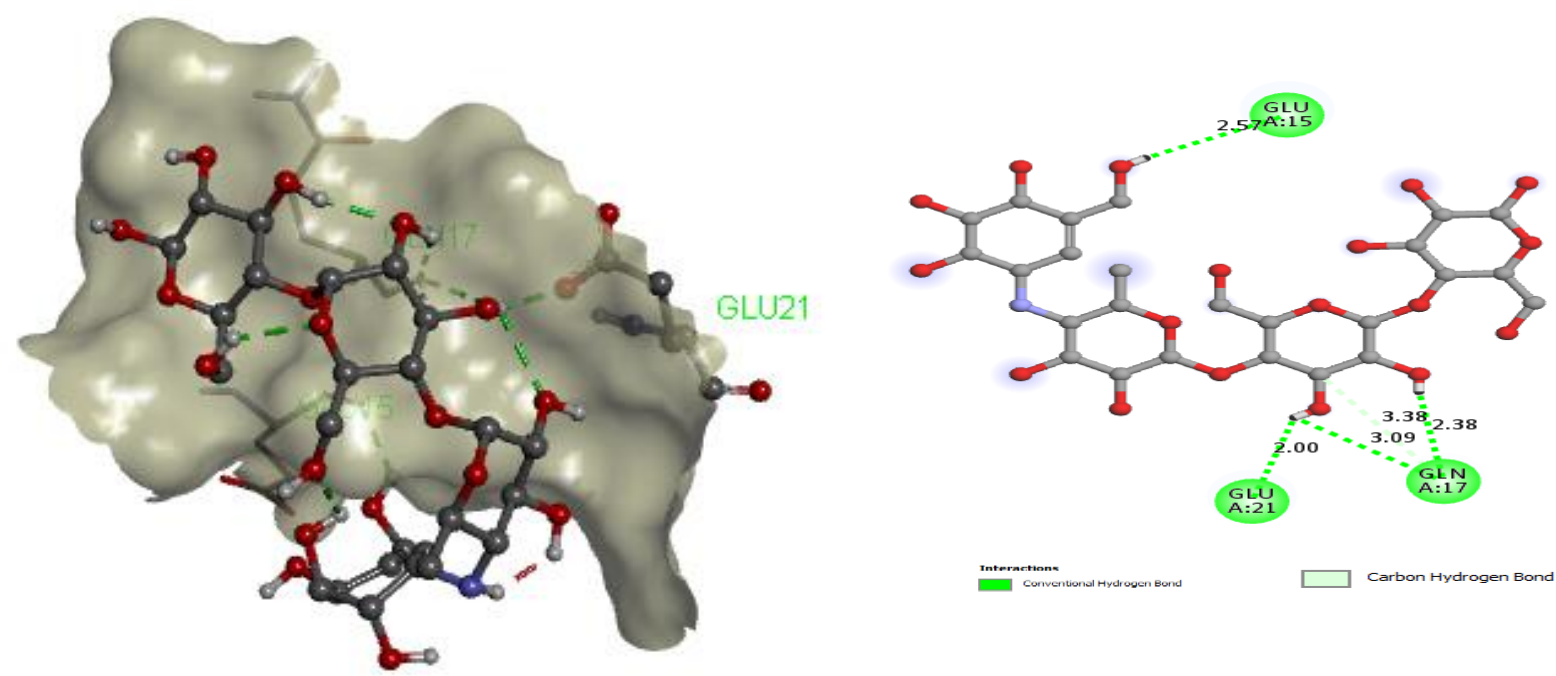

Docking complex and interaction plot for Acarbose with GLP-1 (Binding affinity: $-4.7 \mathrm{kcal} / \mathrm{mol}$ )

Figure 4 - Molecular interactions of $\beta$-Amyrin \& Acarboseb with GLP-1 

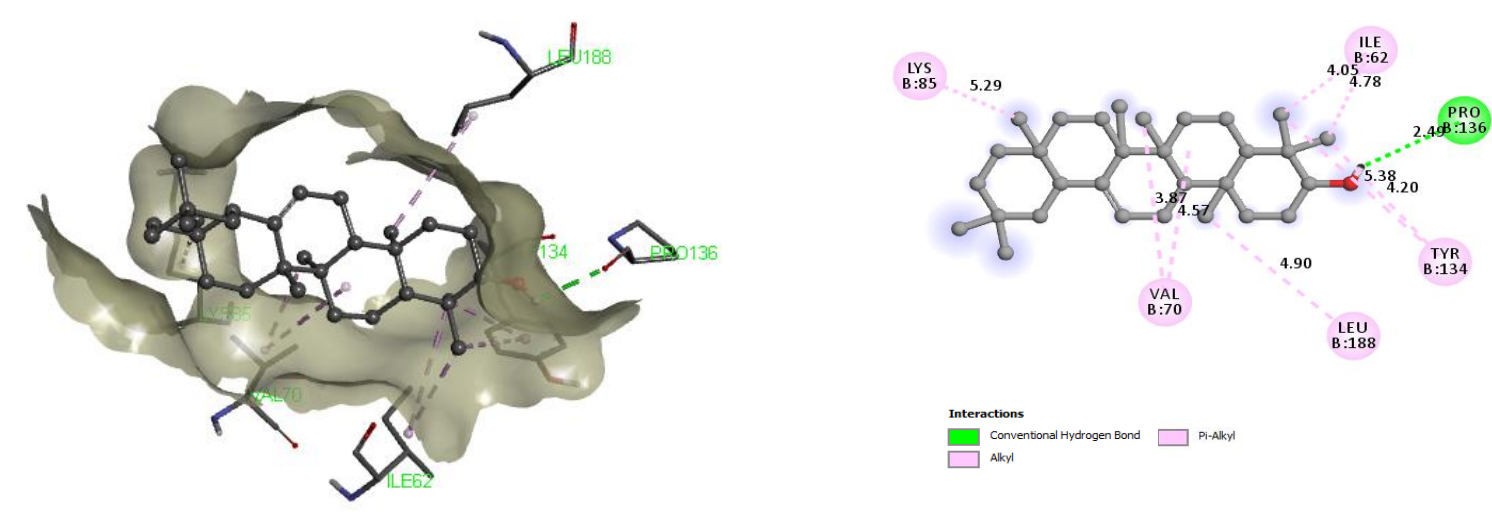

Docking complex and interaction plot for $\beta$-Amyrin with GSK (Binding affinity: $-9.1 \mathrm{kcal} / \mathrm{mol}$ )
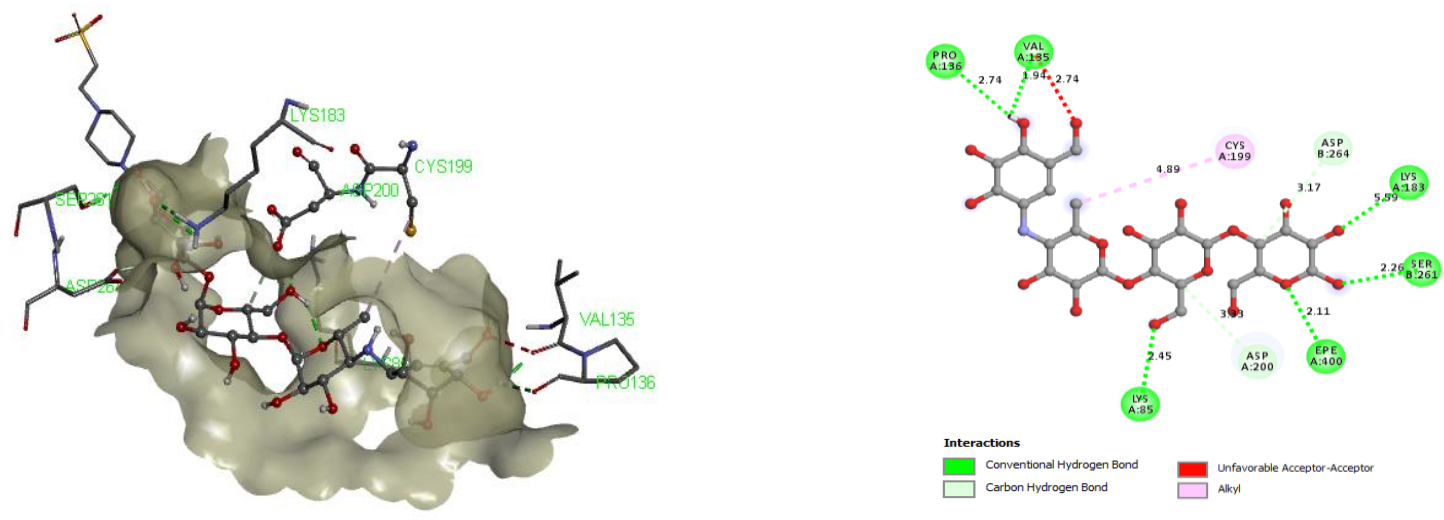

Docking complex and interaction plot for Acarbose with GSK (Binding affinity: $\mathbf{- 8 . 1} \mathrm{kcal} / \mathrm{mol}$ )

Figure 5 - Molecular interactions of $\beta$-Amyrin \& Acarboseb with GSK
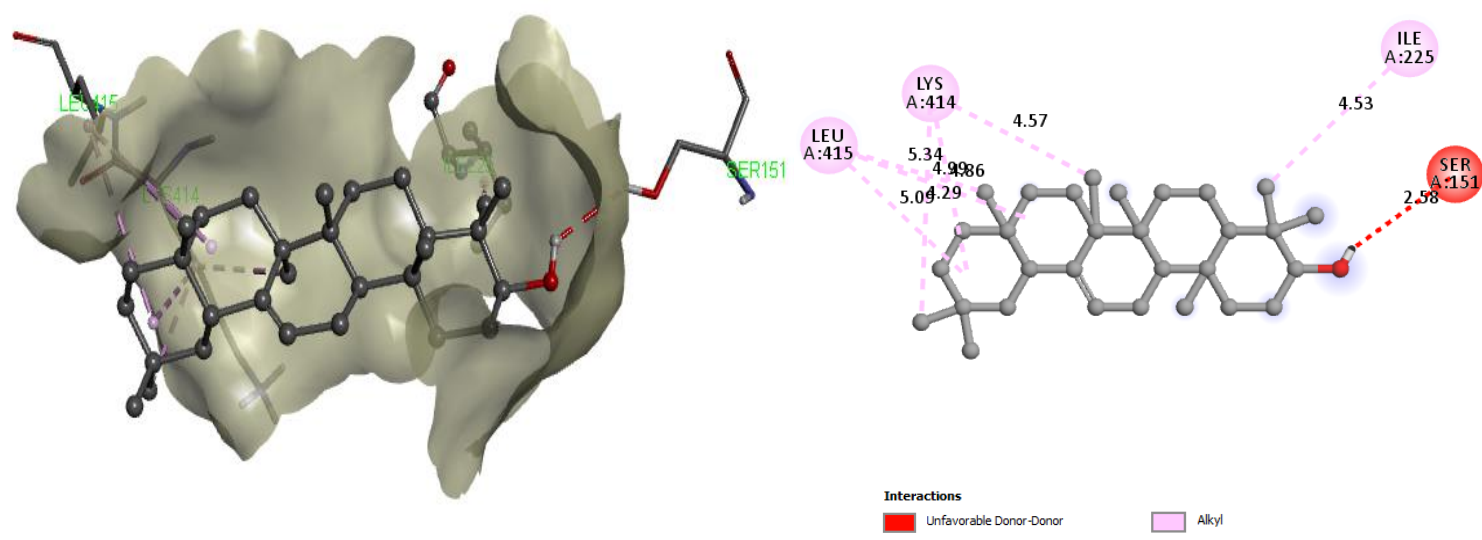

Docking complex and interaction plot for $\beta$-Amyrin with GK (Binding affinity: $\mathbf{- 8 . 2} \mathrm{kcal} / \mathrm{mol}$ ) 

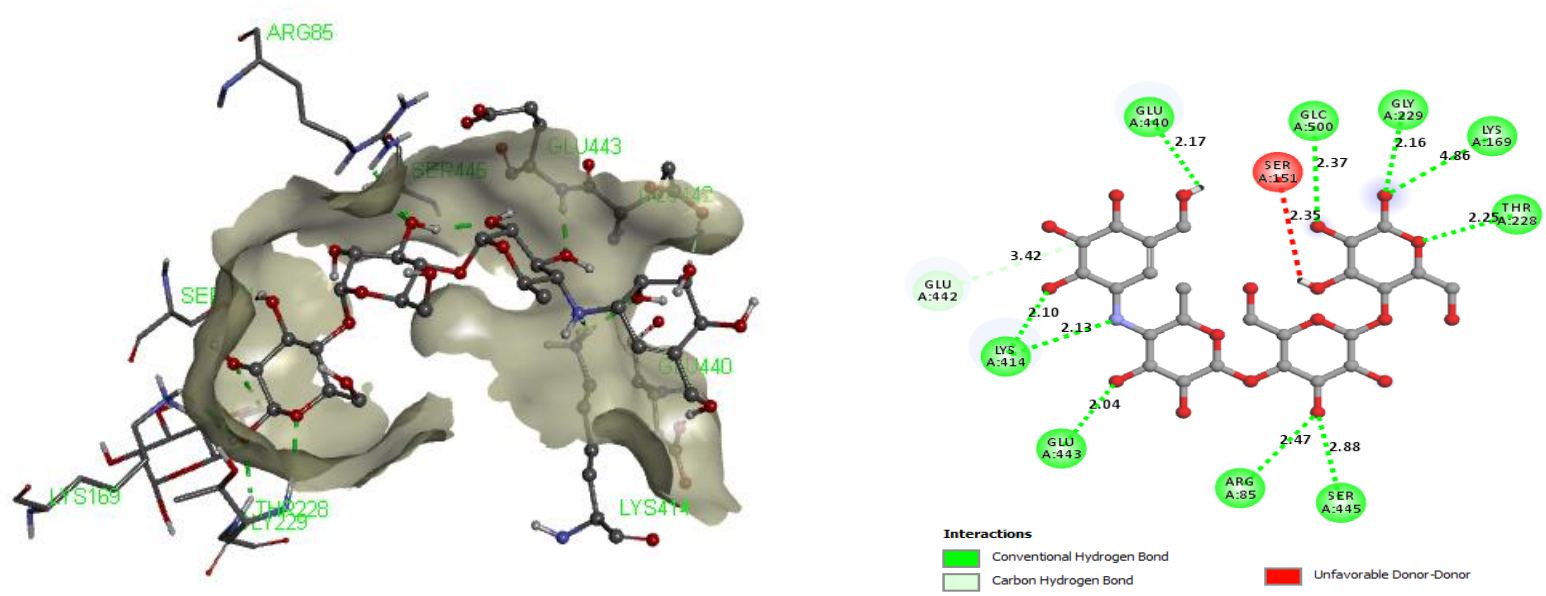

Docking complex and interaction plot for Acarbose with GK (Binding affinity: $-\mathbf{7 . 7} \mathrm{kcal} / \mathrm{mol}$ )

Figure 6 - Molecular interactions of $\beta$-Amyrin \& Acarboseb with GK
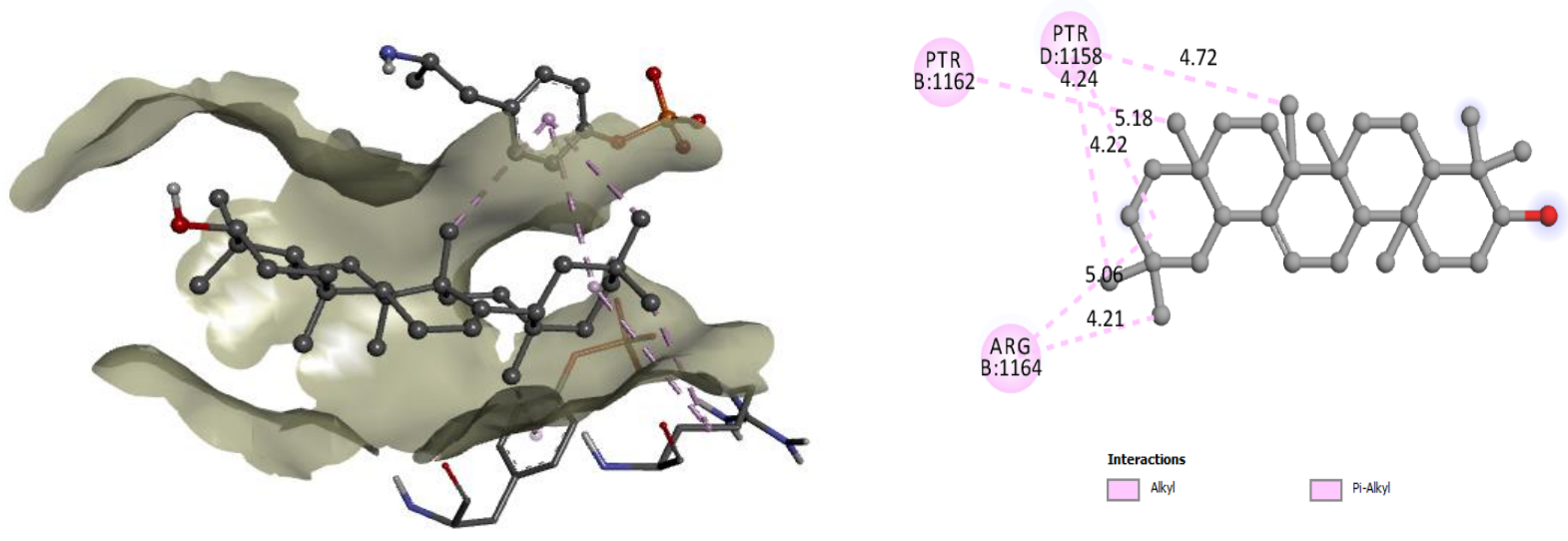

Docking complex and interaction plot for $\beta$-Amyrin with IRTK (Binding affinity: $\mathbf{- 1 0 . 7} \mathbf{k c a l} / \mathbf{m o l}$ )
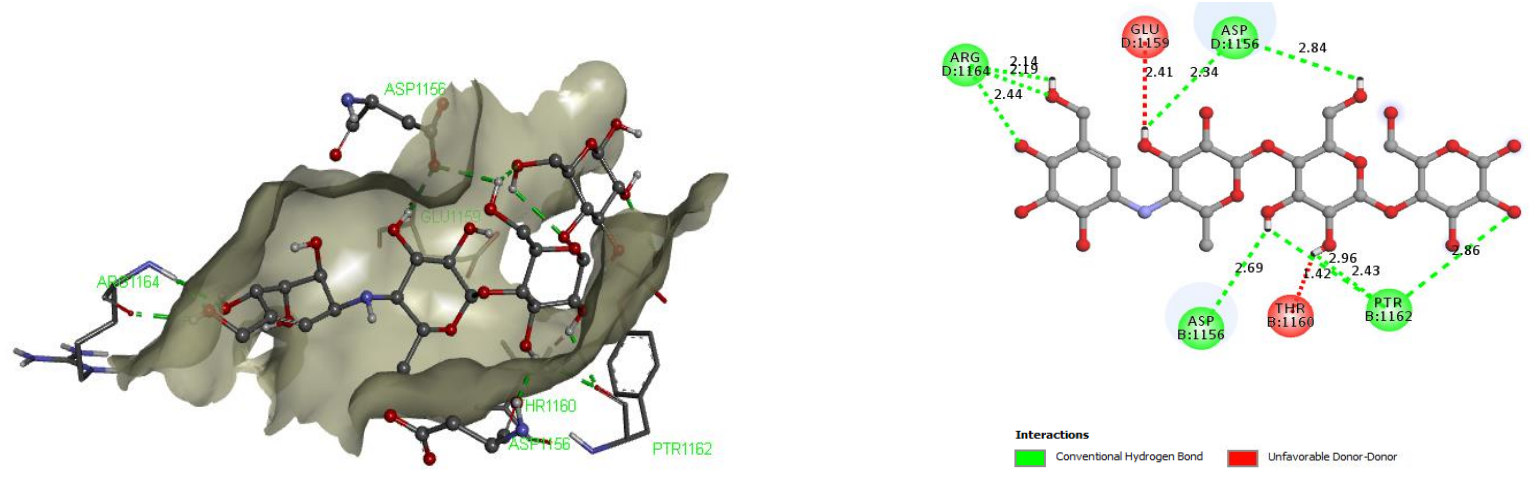

Docking complex and interaction plot for Acarbose with IRTK (Binding affinity: -8.8 kcal/mol) Figure 7 - Molecular interactions of $\beta$-Amyrin \& Acarboseb with IRTK 
Table 5-DFT calculations pertaining to the molecular chemical reactivity of compounds

\begin{tabular}{|c|c|c|c|c|c|c|c|c|c|}
\hline Compound & Hомо & LUMO & Energy Gap & $\begin{array}{c}\text { Ionization } \\
\text { potential } \\
\text { (IE) } \\
\text { (eV) }\end{array}$ & $\begin{array}{c}\text { Electron } \\
\text { affinity } \\
\text { (EA) } \\
\text { (eV) }\end{array}$ & $\begin{array}{c}\text { Electro } \\
\text { negativity } \\
(\chi) \\
(\mathrm{eV})\end{array}$ & $\begin{array}{c}\text { Electro } \\
\text { chemical } \\
\text { potential }(\mu) \\
(\mathrm{eV})\end{array}$ & $\begin{array}{c}\text { Hardness } \\
(\eta) \\
(\mathrm{eV})\end{array}$ & $\begin{array}{c}\text { Softness } \\
(\sigma) \\
(\mathrm{eV})\end{array}$ \\
\hline$\beta$-Amyrin & -0.20105 & -0.13828 & -0.06277 & 0.20105 & 0.13828 & 0.169665 & -0.169665 & 0.031385 & 31.86235 \\
\hline Betulinic acid & -0.22669 & 0.01318 & -0.23987 & 0.22669 & -0.01318 & 0.106755 & -0.106755 & 0.119935 & 8.33784 \\
\hline Stigmasterol & -0.22811 & 0.04114 & -0.26925 & 0.22811 & -0.04114 & 0.093485 & -0.093485 & 0.134625 & 7.42804 \\
\hline Acarbose & -0.21057 & 0.03379 & -0.24436 & 0.21057 & -0.03379 & 0.08839 & -0.08839 & 0.12218 & 8.18464 \\
\hline
\end{tabular}

\begin{tabular}{|c|c|c|}
\hline $\begin{array}{c}\text { PHYTOCOMPOUND/ } \\
\text { DRUG }\end{array}$ & HOMO ORBITAL ENERGY & LUMO ORBITAL ENERGY \\
\hline B-Amyrin & & \\
\hline Stigmasterol & & \\
\hline Acarbose & & \\
\hline & & \\
\hline
\end{tabular}

Figure 8 - HOMO-LUMO orbital energies for phytocompounds $\beta$-amyrin, betulinic acid, stigmasterol identified from F.racemosa and reference standard acarbose.

\section{CONCLUSION}

The phytocompounds from methanolic bark extract of The accurate structural and electronic properties of Ficus racemosa possess most prominent anti-diabetic above phyto compounds by in silico molecular modeling triterpenes and phytosterol class molecules such as $\beta$ - studies proved that the Ficus racemosa phyto amyrin, betulinic acid and stigmasterol, $\beta$-sitosterol compounds to be used for designing novel drug respectively, which is ultimately responsible for their candidate with better therapeutic index for various maximal In vitro and In silico anti-diabetic activity of diabetic targets.

Ficus racemosa over the reference standard acarbose.

\section{Thirumalaisamy Rathinavel et al.,}




\section{REFERENCES}

[1]. Vats V, Yadav SP, and Grover JK, 2004. Ethanolic extract of Ocimum sanctum leaves partially attenuates streptozotocin-induced alterations in glycogen content and carbohydrate metabolism in rats, Journal of Ethnopharmacology, 90 (1):155-160.

[2]. Kumar GPS, Arulselvan P, Kumar DS, and Subramanian SP. 2006. Anti-diabetic activity of fruits of Terminalia chebula on streptozotocin induced diabetic rats. Journal of Health Science. 52 (3): 283-291.

[3]. Sumana G and Suryawashi SA. 2001. Effect of vinca rosea extracts in treatenent of alloxan diabetes in male albino rats. Indian Journal of Experimental Biology.39: 748-758.

[4]. Holman RR and Turner RC. 1991. Oral agents and insulin in the treatment of NIDDM. Text Book of Diabetes. J. Pickup and G. Williams, Eds. Blackwell, Oxford, UK. pp. 467-469,

[5]. Kameswara Rao B, Kesavulu MM, and Apparao Ch. 2001.Antihyperglycemic activity of Momordica cymbalaria in alloxan diabetic rats, Journal of Ethnopharmacology, 78 (1): 67-71.

[6]. Kameswrarao B, Giri R, Kesavalu MM, and Apparao Ch, 1997. "Herbal medine," in The Management by Indigenous Resources, J. S. Bajaj, Ed., Diabetes Mellitus in Developing Countries. Interprint, New Delhi, India. pp. 375-377.

[7]. Joy PP, Thomas J, Mathew S, Skaria BP. 2001. Medicinal Plants, Tropical Horticulture. 2 : 123 125.

[8]. Satish A Bhalerao, Deepa R Verma, Nikhil C Teli, Vinodkumar S Didwana and Saurabh S Thakur, 2014, Ficus racemosa Linn. : A Comprehensive Review. Journal of Applicable Chemistry. 3 (4):1423-1431.

[9]. Arora AK. 2012. American Journal of PharmTech Research. 2(3): 391.

[10]. Paarakh PM, 2009. Ficus racemosa Linn.-An overview. Nat Prod Radiance. 8:84-90.

[11]. Husain A, Virmani OP, Popli SP, Misra LN, Gupta MM, Srivastava GN, Abraham Z, Singh AK. 1992. Dictionary of Indian Medicinal Plants, CIMAP, Lucknow, India, 546.

[12]. Chopra RN, Nayar SL, Chopra IC. 1986. Glossary of Indian Medicinal Plants, CSIR: New Delhi. 119120.

[13]. Prabhakar YS, Suresh KD. 1990. A survey of cardio-active drug formulations from Ayurveda II: porridges, oils, clarified butters, electuaries, pastes, ash preparations and calcined powders. Fitoterapia. 61: 395416.

[14]. Vedavathy S, Rao DN. 1995. Herbal folk medicine of Tirumala and Tirupati region of chittoor. District, Anthra Pradesh. Fitoterapia. 66: 167171.

[15]. Ratnasooriya WD, Jayakody JR, Nadarajah T. 2003. Antidiuretic activity of aqueous bark extract of Sri Lankan Ficus racemosa in rats, Acta Biol Hungary. 54:357-363.
[16]. Biswas TK, Mukherjee B. 2003. Plant medicines of Indian origin for woundhealing activity: a review. Int J Low Extreme Wounds. 2:25-39.

[17]. Odeyemi SW. 2015. A comparative study of the in vitro antidiabetic properties, cytotoxicity and mechanism of action of Albuca bracteata and Albuca setosa bulb extracts Doctoral dissertation [Doctoral, thesis], University of Fort Hare.

[18]. Berman, HM. 2000. The protein data bank. Nucleic Acids Res. 28: 235-242.

[19]. Weininger D. 1988. SMILES, a chemical language and information system. Introduction to methodology and encoding rules, Journal of Chemical Information and Computer Sciences. 28:31-36

[20]. Trott O, Olson.AJ. 2010. AutoDock Vina: improving the speed and accuracy of docking with a new scoring function, efficient optimization and multithreading, Journal of Computational Chemistry 31:455-461.

[21]. Thirumalaisamy R, Vaijayanthimala $M$, Govindaraju S and Subramanian A . 2015. Phytochemical Screening and GC-MS Analysis of Madhuca longifolia (L) Macbr. Int. J. Adv. Sci. Eng. Vol. 2 No.2 87-92

[22]. Thirumalaisamy Rathinavel, Subramanian Ammashi, Govarthanan Muthusamy. 2018. Screening of anti-inflammatory phytocompounds from Crateva adansonii leaf extracts and its validation by in silico modeling. Journal of Genetic Engineering and Biotechnology 16: 711-719.

[23]. Balamurugan R, Stalin A, Ignacimuthu S. 2012. Molecular docking of $\gamma$-sitosterol with some targets related to diabetes. Eur J Med Chem. 47: 38-43.

[24]. Kamata K, Mitsuya M, Nishimura T, Eiki J, Nagata Y. 2004. Structural basis for allosteric regulation of the monomeric allosteric enzyme human glucokinase. Structure. 12: 429-438.

[25]. Osolodkin DI, Palyulin VA, Zefirov NS. 2011. Structure-based virtual screening of glycogen synthase kinase $3 \beta$ inhibitors: analysis of scoring functions applied to large true actives and decoy sets. Chem Biol Drug Des. 78: 37890.

[26]. Akhtar M, Bharatam PV. 2012.3D-QSAR and molecular docking studies on 3-anilino-4arylmaleimide derivatives as glycogen synthase kinase- $3 \beta$ inhibitors. Chem Biol Drug Design. 79: 560-71.

[27]. Khanfar MA, Hill RA, Kaddoumi A, El Sayed KA. 2010. Discovery of novel GSK-3 $\beta$ inhibitors with potent in vitro and in vivo activities and excellent brain permeability using combined ligand- and structure-based virtual screening. Journal of medicinal chemistry. 53: 8534-45. 
[28]. Akhila S, Aleykutty NA. and Manju P. 2012. Docking studies on Peperomiapellucida as antidiabetic drug. International Journal of Pharmacy and Pharmeutical Sciences. 4(4), 7677.

[29]. Arumugam Madeswaran. Muthuswamy Umamaheswar i. Kuppusamy Asok kumar. Thirumalaisamy Sivashanmugam. Varadharajan Subhadradevi. Puliyath Jagannath. 2012. In silico docking studies of aldose reductase inhibitory activity of commercially available flavonoids. Bangladesh J Pharmacol. 7 : 266-271.
[30]. Antony P, Vijayan R. 2015. Identification of Novel Aldose Reductase Inhibitors from Spices: A Molecular Docking and Simulation Study. PLoS One. 10(9),1-19

[31]. Mayara Amoras Teles Fujishima, Nayara dos Santos Raulino da Silva, Ryan da Silva Ramos et al., 2018. An Antioxidant Potential, Quantum-Chemical and Molecular Docking Study of the Major Chemical Constituents Present in the Leaves of Curatella americana Linn. Pharmaceuticals (Basel). 11(3): 72.

All (c) 2019 are reserved by International Journal of Advanced Science and Engineering. This Journal is licensed under a Creative Commons Attribution-Non Commercial-ShareAlike 3.0 Unported License. 